April 2019 Volume 2 No 2

\title{
APPLICATION OF CANVAS MODEL BUSINESS ANALYSIS: CASE STUDY OF FREE POWER BUSINESS
}

\section{PENERAPAN ANALISIS BISNIS MODEL KANVAS : STUDI KASUS USAHA FREE POWER}

\author{
Diki Ramadani ${ }^{1}$, Joko Susanto ${ }^{1}$, Riska Apri Arianti ${ }^{1}$, \\ $\left.{ }^{1}\right)$ Jurusan Agribisnis Fakultas Pertanian, Universitas Muhammadiyah Sumatera Utara \\ Jalan Kapten Mukhtar Basri No. 3 Medan \\ Email: dikiramadani35@gmail.com, freepower77@yahoo.com
}

\begin{abstract}
One of the technological tools that can not be separated from people's lives is cellphones, but the consequences of increasingly sophisticated technological tools are the higher power requirements. Current technology has developed into portable tools, namely tools that do not need to be connected directly to the main source of electric current but use the power stored in the battery, FREE POWER is a business that is engaged in Powerbank, where the product of the power source Free Power utilizes magnetic energy generator that can be used continuously without having to worry about running out of power. The types and sources of data used in this study are qualitative, the data needed in this study are primary data and secondary data. FREE POWER in the form of an innovative charging device on a smartphone by utilizing a magnetic generator that has the advantage of being able to charge continuously without having to recharge. With a cheaper price compared to a power bank. FREE POWER is the right solution to support the smooth use of the smartphone itself, so that the operation is not constrained due to the depletion of the smartphone battery used. And for consumers themselves are intended for teenagers to adults.
\end{abstract}

Keywords: Business Model Canvas, Powerbank, Free Power

\begin{abstract}
Abstrak
Salah satu alat teknologi yang tidak lepas dari kehidupan masyarakat adalah handphone, Namun konsekuensi dari semakin canggihnya alat teknologi yaitu kebutuhan daya yang juga semakin tinggi. Teknologi sekarang ini telah berkembang menjadi alat-alat portable, yaitu alat yang tidak perlu dihubungkan langsung ke sumber utama arus listrik tetapi memakai daya yang disimpan di dalam baterai, FREE POWER adalah sebuah usaha yang bergerak pada bidang Powerbank, dimana produk produk pengisidaya Free Power memanfaatkan energy generator magnetic yang dapat digunakan secara terus menerus tanpa harus khawatirakan habisnya daya. Jenis dan sumber data yang digunakan dalam penelitian ini adalah kualitatif, Data yang diperlukan dalam penelitian ini yaitu data primer dan data skunder. FREE POWER berupa inovasi alat pengisi daya pada smartphone dengan memanfaatkan generator magnetic yang memiliki keunggulan dapat mengisi daya secara terus menerus tanpa harus melakukan pengisian ulang. Dengan harga yang lebih murah di bandingkan dengan power bank. FREE POWER ini merupakan solusi tepat untuk menunjang kelancaran pengunaan smartphone itu sendiri, sehingga dalam pengoperasiannya tidak terkendala dikarenakan habisnya daya batrai smarphone yang digunakan. Dan untuk konsumennya sendiri diperuntukan untuk remaja hingga orang dewasa.
\end{abstract}

Kata Kunci: Business Model Canvas, Powerbank, Free Power

\section{A. PENDAhUluAN}

Perkembangan bisnis di Indonesia semakin menuju ke arah yang positif. Hal ini di tunjukkan dengan banyaknya industri-industri yang muncul dari skala yang besar maupun skala yang kecil. Industri yang paling banyak berkembang yaitu industri makanan dan minuman. Industri makanan dan minuman memiliki peranan penting dalam pertumbuhan ekonomi di Indonesia. Data menunjukkan, bahwa pertumbuhan dan nilai investasi di sektor pangan selalu meningkat dalam beberapa tahun terakhir (Gapmmi, 2016).

Sistem Energi Surya Fotovoltaik (SESF) selain dapat digunakan untuk program listrik pedesaan, peluang pemanfaatan energi surya lainnya seperti lampu penerangan jalan dan lingkungan. Pada SESF ini juga masih perlu ada beberapa pengembangan yaitu pada manajemen pengisian 
baterai, untuk mecegah kerusakan yang dihasilkan kualitas daya, yaitu tegangan yang tidak teratur kadang terlalu tinggi dan kadang terlalu rendah. SESF terdiri panel PV yang mengubah sinar matahari menjadi arus searah (DC), charging circuits untuk pengisian baterai, sistem pengisi baterai bertugas sebagai jantung SESF, kemudian baterai digunakan untuk penyimpanan daya listrik. Pada penelitian ini SESF yang digunakan adalah dengan sumber stand alone power system (SAPS) sehingga semua energi yang dihasilkan PV disimpan pada baterai. Sehingga yang sangat diperhatikan dalam penelitian ini terfokuskan pada sistem ini adalah sistem pengisi baterai untuk baterai yang tujuan untuk mengatur konsumsi hasil konversi energi listrik pada PV (Dankate, 2014)Handphone atau biasa disebut Telepon Genggam atau yang sering dikenal dengan nama Ponsel merupakan perangkat telekomunikasi elektronik yang mempunyai kemampuan dasar yang sama de-ngan telepon konvensional saluran tetap, namun dapat dibawa ke mana-mana (portabel, mobile) dan tidak perlu disambungkan dengan jaringan telepon menggunakan kabel (nirkabel; wireless

Salah satu alat teknologi yang tidak lepas dari kehidupan masyarakat adalah handphone. Dulu handphone hanya bisa menjadi alat komunikasi saja semisal alat untuk telepon, sms, dan radio. Kini handphone telah berevolusi menjadi tidak hanya alat komunikasi saja, tetapi juga alat yang mampu menjalankan sebagian kemampuan kerja dari komputer sekalipun. Sehingga tidak heran sekarang ini telah berubah trend dari handphone menjadi smartphone, yaitu handphone yang memiliki kemampuan menggantikan sebagian kinerja dari computer

Sebagian besar energi yang hilang dalam sebuah charger ponsel ini tidak dalam kondisi berbeban, ketika ponsel ini tidak tersambung dengan pengisi daya tetapi pengisi daya terpasang maka tetap menyerap daya.

Perkembangan teknologi yang semakin canggih menuntut untuk berfikir sesuatu hal yang lebih mudah dan meringankan pekerjaan. Apalagi dengan kesibukan aktifitas dan mobilitas yang tinggi memang sudah menjadi gaya hidup sebagian besar masyarakat perkotaan. Handphone jelas membutuhkan baterai yang dapat berfungsi sebagai sumber energi. Tetapi sangat disayangkan bila ternyata aktifitas yang harus dilakukan diluar ruangan terhambat oleh karena kondisi baterai yang drop atau mau habis

Namun konsekuensi dari semakin canggihnya alat teknologi yaitu kebutuhan daya yang juga semakin tinggi. Teknologi sekarang ini telah berkembang menjadi alat-alat portable, yaitu alat yang tidak perlu dihubungkan langsung ke sumber utama arus listrik tetapi memakai daya yang disimpan di dalam baterai. Dengan semakin besar kapasitas yang dimiliki baterai maka semakin lama handphone bias bertahan. Namun konsekuensi alat portable jika daya di dalam baterai telah habis maka daya harus diisi ulang(Donnel, Henri. 2005). Pengisian daya membutuhkan sumber arus listrik yang bisa mengisi daya pada baterai. Namun jika tidak bisa menemukan sumber arus listrik maka daya tidak dapat diisi ulang

Pertumbuhan produk smartphone memang luar biasa di dunia termasuk di Indonesia ,periode Maret 2012 2013, kepemilikan smartphone di Indonesia naik dua kali lipat, dari $12 \%$ menjadi $24 \%$ dari total populasi Indonesia. Sementara itu pengguna telepon seluler naik $10 \%$ mencapai $84 \%$ dari total populasi Indonesia pada Maret 2013. Produk smartphone yang menguasai pangsa pasar di Indonesiadi perkenalkan oleh beberapa perusahaan besar .

FREE POWER adalah sebuah usaha yang bergerak pada bidang Powerbank, dimana produk produk pengisidaya Free Power memanfaatkan energy generator magnetic yang dapat digunakan secara terus menerus tanpa harus khawatirakan habisnya daya. Chesbrought (2006) mengemukakan bahwa strategi usaha yang dijalankan oleh perusahaan tidak akan dapat berjalan maksimal jika tidak didasari oleh pengkajian dan perumusan model bisnis yang tepat.

Untuk itu, dibutuhkan konsep model bisnis yang tepat bagi perusahaan untuk menumbuh kembangkan kegiatan bisnisnya. Model bisnis dibutuhkan dalam mengidentifikasi fitur-fitur ekonomi pasar yaitu pilihan pelanggan, biaya transaksi, heterogenitas diantara pelanggan dan produsen, dan persaingan .

Salah satu konsep model bisnis yang akan dipakai penulis adalah model bisnis kanvas. Model bisnis kanvas yang biasa disebut BMC (Busines Model Canvas) ini merupakan model bisnis yang dikembangkan dan dipublikasikan oleh Osterwalder danPigneur pada tahun 2010. Analisis perusahaan dengan menggunakan Business Model Canvas (BMC) dinilai efektif karena analisis yang digunakan dijelaskan secara menyeluruh baik dari segi pemasaran, sumber daya manusia, keuangan, sampai dengan nilai atau produk yang ditawarkan. Sehingga pengusaha bisa menentukan arah bergerak bagi perusahaan serta mengetahui keunggulan bersaing yang ada pada bisnis yang sedang dijalankannya (Suharti, 2015). BMC mengijinkan bisnis untuk memahami bagaimana setiap komponen berhubungan satu sama lain dalam jangka fungsi, aktivitas, dan proses berjalannya bisnis tersebut 


\section{APPLICATION OF CANVAS MODEL BUSINESS ANALYSIS}

Business model canvas membantu mendeskripsikan, menganalisa dan merancang model bisnis secara inovatif dalam upaya menciptakan,memberikan dan menangkap nilai untuk dapat memasuki wilayah baru, menciptakan ruang pasar dan membangkitkan permintaan melalui inovasi nilai. Model bisnis kanvas ini disajikan dalam bentuk visual berupa suatu kanvas lukisan sehingga sangat memudahkan untuk dimengerti oleh yang menyimaknya. Banyak dalam model bisnis canvas ini yang bisa dipilih dan pihak perusahaan bisa menyesuaikannya sesuai dengan kebutuhan perusahaannya (Pigneur, 2010)

kanvas model bisnis adalah Bahasa yang sama untuk menggambarkan, memvisualisasikan, me-nilai dan mengubah model bisnis. Sedangkan definisi model bisnis adalah sebuah model bisnis menggambarkan dasar pemikiran tentang bagaimana organisasi menciptakan, memberikan, dan menangkap nilai.

\section{B. METODE PENELITIAN}

Penelitian ini menggunakan jenis penelitian kualitatif. Penelitian kualitatif adalah penelitian yang bertujuan untuk memahami suatu fenomena mengenai apa yang dialami oleh subjek penelitian secara holistik, dengan cara deskripsi dalam bentuk kata-kata dan bahasa, pada suatu konteks khusus yang alamiah dan dengan memanfaatkan berbagai macam metode ilmiah.

Jenis dan sumber data yang digunakan dalam penelitian ini adalah kualitatif. Data kualitatif adalah dokumen pribadi, catatan lapangan, dan dokumen pendukung. Data kualitiatif berfungsi untuk mengetahui kualitas dari objek yang diteliti. Data yang diperlukan dalam penelitian ini yaitu data primer dan data skunder. Data primer adalah data penelitian yang diperoleh dari sumber data pertama di lokasi penelitian atau subjek penelitian. Data sekunder adalah data yang didapatkan dari sumber data kedua dari data yang dibutuhkan.

\section{HASIL DAN PEMBAHASAN Gambaran Umum}

Salah satu alat komunikasi yang terbilang sangat di gemari masyarkat adalah smartphone. Lembaga riset digital marketing Emarket mermemperkirakan pada 2018 jumlah pengguna aktif smartphone di Indonesia lebih dari 100 juta orang. Dengan jumlah sebesar itu, Indonesia akan menjadi negara dengan pengguna aktif smartphone terbesar keempat di dunia setelah Cina, India, dan Amerika. Namun seiring dengan kemajuan ini daya simpan baterai Smartphone belum mampu mengimbangi berbagai aplikasi yang di gunakan dalam smartphone.
Kesibukan dengan aktifitas dan mobilitas yang tinggi memang sudah menjadi gaya hidup sebagian besar masyarakat pada umumnya. Hal ini menyebabkan sarana alat komunikasi, seperti smartphone menjadi hal yang sangat dibutuhkan. Smartphone jelas membutuhkan baterai yang berfungsi sebagai sumber energi. Tetapi sangat disayangkan bila ternyata aktifitas yang harus dilakukan diluar ruangan terhambat karena kondisi energi baterai yang cepat habis. Hal ini membuat orang sering membawa powerbank ke mana mereka pergi. Powerbank juga menggunakan baterai dalam pengoperasiannya, yang bisa mengisi alat lain yang membutuhkan daya isi baterai, akan tetapi powerbank pun tidak memiliki daya yang tidak pernah habis, dalam artian saat daya baterai yang ada dalam powerbank habis, maka kita perlu mengisinya dan bisa menggunakannya lagi. Salah satu kesalahan fatal pengguna power bank adalah membiarkan sampai habis baru kemudian dicharge. Ini adalah cara yang salah sehingga menyebabkan powerbank cepat rusak.

Maka sangat potensial bila kami mengembangkan usaha FREE POWER ini karena sebagian besar masyarakat sangat membutuhkan alat pengisi daya smartphone, terutama pada saat berada di luar ruangan dan tidak ada sumber listrik. FREE POWER berupa inovasi alat pengisi daya pada smartphone dengan memanfaatkan generator magnetic yang memiliki keunggulan dapat mengisi daya secara terus menerus tanpa harus melakukan pengisian ulang. Dengan harga yang lebih murah di bandingkan dengan power bank yang mencapai hingga Rp.350.000 atau bahkan lebih,

\section{Identifikasi Sembilan Elemen Business Model Canvas \\ 1. Customer Segments}

Customer segments mendefinisikan kelompok yang berbeda dari orang atau organisasi suatu perusahaan yang bertujuan untuk menjangkau dan melayani. Model bisnis harus didesain dengan pemahaman yang kuat akan kebutuhan pelanggan. FREE POWER adalah alat pengisi daya smartphone tanpa batas, customer segmen akan menentukan siapa pengguna dari produk free power ini yaitu mulai dari kalangan remaja sampai kalangan dewasa yang sedang menggunakan smartphone.

\section{Value Propositions}

Value Propositions adalah alasan yang membuat pelanggan beralih dari satu perusahaan ke perusahaan lain. Proposisi nilai pelanggan ini adalah alat yang terpenting dalam pemasaran produk. Dengan tidak adanya proposisi nilai pelanggan, perusahaan tidak berjalan dengan benar di pasar. FREE POWER berupa inovasi alat pengisi daya pada smartphone 
dengan memanfaatkan generator magnetic yang memiliki keunggulan dapat mengisi daya secara terus menerus tanpa harus melakukan pengisian ulang. Dengan harga yang lebih murah di bandingkan dengan power bank yang mencapai hingga Rp.350.000 atau bahkan lebih, maka produk ini dapat bersaing di pasar.

\section{Channels}

Channels juga dapat diartikan sebagai sarana bagi perusahaan untuk berhubungan dengan pelanggannya. Channels merupakan cara untuk meningkatkan kesadaran, memudahkan pelanggan menilai, membantu pelanggan membeli produk atau jasanya, menyampaikan produk / jasa, memberi bantuan paska pembelian. Proses pembelian yang dilakukan oleh FREE POWER terbagi menjadi dua yaitu proses yang terjadi secara langsung dan secara tidak langsung (kontak melalui media online ). Bagi customer yang memesan, diberikan dua pilihan yaitu ambil sendiri atau pemilik yang mengantarkan. Sistem pembayaran yang dilakukan secara langsung memiliki dua opsi yaitu membayar secara cash dan debit sedangkan bagi transaksi yang dilakukan secara tidak langsung dapat melakukan sistem COD di mana pembayaran secara cash pada saat barang diantarkan dan sistem transfer di mana customer diminta untuk mentransfer sejumlah uang sesuai dengan total harga barang dan kemudian pemilik akan mengantarkan pesanannya ke rumah.

\section{Customer Relationship}

Customer Relationships bertujuan untuk mendapatkan pelanggan baru, mempertahankan pelanggan lama, serta menawarkan produk dan jasa yang lama maupun yang baru terhadap pelanggan lama dan baru. FREE POWER berusaha semaksimal mungkin untuk menjaga hubungan baik dengan customer. Dapat dikatakan pula bahwa kategori customer relationships yang diterapkan dalam FREE POWER adalah personal assistance (customer berkomunikasi secara langsung dengan owner), dedicated personal assistance (customer khusus dilayani secara khusus oleh owner), communities (owner membuat grup di Whatsapp untuk menjalin hubungan dengan komunitas customernya).

\section{Revenue Stream}

Revenue Streams menggambarkan bagaimana organisasi memperoleh uang dari setiap segmen pelanggan. Aliran dana inilah yang memungkinkan organisasi tetap bertahan hidup.revenue streams menjelaskan bagaimana mekanisme penetapan harga, yang digunakan dalam model bisnis, dapat menangkap nilai (capturing value).pendapatan yang didapatkan FREE POWER dari penjualan produk, Mekanisme harga yang digunakan adalah fixed menu pricing di mana harga ditetapkan berdasarkan kualitas.

\section{Key Resources}

Key resources ialah sumber daya yang memungkinkan organisasi dalam menjalankan key activities untuk menawarkan value proposition, menjangkau pasar, menjaga hubungan dengan customer segments, dan menghasilkan pendapatan. FREE POWER menjaga kualitas produk sehingga customer akan terus menggunakan produk free power tanpa khawatir akan kualitas yang akan menurun sehingga FREE POWER bisa terus bersaing di pasar internasional.

\section{Key Activities}

Key activities merupakan aktivitas-aktivitas perusahaan yang harus dilakukan dengan sangat baik oleh perusahaan. Aktivitas ini merupakan yang paling penting dalam perushaan yang harus diambil untuk mengoperasikan perusahaan dengan sukses. FREE POWER tetap melakukan produksi barang sebagai kegiatan stock produk sehingga customer yang memesan tidak perlu menunggu ketika akan melakukan proses pembelian.

\section{Key Partnership}

Key partnerships dapat dijelaskan sebagai suatu perjanjian kerjasama yang dibangun antara dua perusahaan atau lebih untuk menciptakan nilai bagi pelanggan. Key partnerships merupakan pihak yang menjalin hubungan kerja sama dengan FREE POWER. FREE POWER memiliki partner yang potensial customer yang dapat membantu owner dalam mencapai tujuannya.

\section{Cost Structure}

Biasanya, biaya-biaya perusahaan sebaiknya diminimalkan dalam setiap model bisnis. Cost structure yang rendah akan menjadi lebih penting bagi beberapa model bisnis dibandingkan model bisnis yang lainnya, sehingga hal ini menjadi salah satu pertimbangan dalam usaha. Biaya yang dikeluarkan oleh FREE POWER yaitu biaya perlengkapan, biaya peralatan dan biaya kirim. Karakteristik cost structure FREE POWER yaitu fixed costs (biaya pembelian alat dan bahan untuk pembuatan produk free power) variable costs (biaya bensin untuk mengantar produk ketangan customer).

Analisis SWOT

Analisis SWOT digunakan untuk melakukan evaluasi terhadap kondisi pasar dan keadaan posisi perusahaan dipasar. Hal ini tentunya menjadi kegiatan manajemen untuk menyesuaikan perusahaan dengan keadaan dipasar. Penilaian ini dapat menjadi dasar untuk memperbaiki model bisnis secara bertahap atau dapat melakukan pembaharuan model bisnis perusahaan dalam bentuk inovasi model bisnis. Cara yang paling efektif dalam melakukan yaitu dengan mengobinasikan analisis SWOT dan business 


\section{APPLICATION OF CANVAS MODEL BUSINESS ANALYSIS}

model canvas. Analisis SWOT terdapat empat prespektif dalam menilai elemen-elemen suatu model bisnis yaitu kekuatan dan kelemahan sebuah perusahaan dan mengidentifikasi ancaman dan peluang bagi perusahaan. Business model canvas memberikan fokus yang diperlukan untuk sebuah diskusi yang lebih terstruktur. Analisis SWOT menanyakan pertanyaan tentang internal dan eksternal untuk perusahaan. Bagian internal yaitu kekuatan dan kelemahan perusahaan, sedangkan untuk eksternal yaitu peluang yang dimiliki oleh perusahaan serta potensi ancaman apa yang dihadapi perusahaan

Ada pun analisis SWOT pada usaha FREE POWER adalah sebagai berikut:

Srtengths (kekuatan) produk

1. Bahan baku yang mudah di dapat dan banyak di pasaran.

2. Kualitas bahan baku terjamin sehingga kualitas produk yang di hasilkan juga baik.

3. Harga yang lebih murah dibandingkan dengan Power Bank.

4. Dapat digunakan secara terus menerus tanpa harus melakukan pengecasan ulang seperti Power Bank.

Weaknesses (kelemahan)

1. Belum banyak masyarakat yang mengetahui produk FREE POWER karena merupakan inovasi baru alat pengisi daya baterai smatrphone sehingga di perlukannya pengenalan produk sehingga produk dapat di terima oleh masyarakat.

2. Ukuran produk FREE POWER lebih besar di bandingkan dengan power bank.

\section{Opportunities (Peluang)}

1. Banyaknya pengguna smartphone pada saat ini dan pada 2018 jumlah pengguna aktif smartphone di Indonesia lebih dari 100 juta orang.

2. Memiliki keunggulan lebih baik di bandingkan dengan power bank.

3. Banyaknya aktifitas di luar ruangan yang menggunakan smartphone sehingga produk ini dapat menjadi solusi pada saat daya batrai smrtphone habis.

\section{Treaths (Ancaman)}

1. Memiliki pesaing karena banyak produk sejenis, namun tidak terlalu di khawatirkan dapat mengancam usaha ini, dikarenakan produk FREE POWER ini memiliki keunggulan jauh lebih baik di bandingkan produk sejenis lainnya.
Langkah Strategi Pemasaran Dalam Usaha Ini Yaitu:

1. Strategi Produk

Produk yang di hasilkan menggunakan bahan yang mudah di dapat dan desain produk yang menarik.

2. Strategi Harga

Harga yang di tawarkan terjangkau yaitu Rp. 191.000 jika di bandingkan dengan produk sejenis lainnya yang mencapai hingga Rp. 350.000 .

3. Strategi Tempat

Menggunakan dua cara yaitu dengan cara offline dan online, offline dengan membuka gerai yang berada di Jalan Gelugur Gang Langgar Nomor 4 Medan, dan online dengan memasarkan melalui media online berupa facebook dan instagram.

4. Strategi Promosi

Promosi menggunakan metode penyebaran brosur, promosi secara langsung kepada masyarakat dan secara online dengan membuat akun media sosial berupa facebook dan instagram.

\section{KESIMPULAN DAN SARAN}

Kesimpulan

1. FREE POWER ini merupakan solusi tepat untuk menunjang kelancaran pengunaan smartphone itu sendiri, sehingga dalam pengoperasiannya tidak terkendala dikarenakan habisnya daya batrai smarphone yang digunakan. Dan untuk konsumennya sendiri diperuntukan untuk remaja hingga orang dewasa.

2. FREE POWER merupakan alat pengisi daya tanpa batas yang dimana untuk alat dan bahan bakunya sendiri mudah di dapat karena banyak tersedia di pasar dengan spesifikasi dan model yang beragam

3. Proses pembelian yang dilakukan oleh FREE POWER terbagi menjadi dua yaitu proses yang terjadi secara langsung dan secara tidak langsung (kontak melalui media online ). Dan harga yang ditawarkan free power juga lebih terjangkau jika dibandingkan dengan powerbank.

\section{Saran}

Memperkecil ukuran produk FREE POWER agar lebih efesien ketika digunkan.

\footnotetext{
DAFTAR PUSTAKA

[1] Anomimous. (2011). Tenaga Surya, (http:// www.tenaga-surya.com
} 
[2] Anomimous. (n.d.). Telepon Genggam, (http://id.wikipedia.org/wiki/Telepon genggam.

[3] Dankate, A. (2014). "Power Optimization of Battery Charging System Using FPGA Based Neural Network Controller", Int. Journal of Engineering Research and Applications, . 112-122.

[4] lukman, A. w. (2011). Membuat Sendiri Charger HP USB Portable Universal, (http://lukmannet.blogspot.com/).

[5] Pigneur, O. A. (2010). Business model generation 